\title{
SOME PERTURBED VERSIONS OF THE GENERALIZED TRAPEZOID TYPE INEQUALITIES FOR TWICE DIFFERENTIABLE FUNCTIONS
}

\author{
HÜSEYIN BUdAK AND SAMAD NOEIAGHDAM
}

\begin{abstract}
In this study, we first obtain an identity for twice differentiable functions. Then we establish some new perturbed trapezoid type integral inequalities for functions whose first derivatives either are of bounded variation or Lipschitzian. Moreover, some perturbed versions of trapezoid type inequalities for mapping whose second derivatives are bounded, of bounded variation or Lipschitzian, respectively.
\end{abstract}

Mathematics subject classification (2010): 26D15, 26A45, 26D10.

Keywords and phrases: Function of bounded variation, perturbed trapezoid type inequalities, RiemannStieltjes integrals.

\section{REFERENCES}

[1] M. W. AlOMARI, A Generalization of weighted companion of Ostrowski integral inequality for mappings of bounded variation, RGMIA Research Report Collection, 14(2011), Article 87, 11 pp.

[2] M. W. Alomari And M. A. LATIF, Weighted companion for the Ostrowski and the generalized trapezoid inequalities for mappings of vounded variation, RGMIA Research Report Collection, 14(2011), Article 92, $10 \mathrm{pp}$.

[3] M. W. Alomari And S. S. Dragomir, Mercer-Trapezoid rule for the Riemann-Stieltjes integral with applications, Journal of Advances in Mathematics, 2(2)(2013), 67-85.

[4] M. W. AlOMARI, A companion of Ostrowski's inequality with applications, TJMM, vol. 3, no. 1, pp. 9-14, 2011.

[5] M. W. Alomari, A companion of the generalized trapezoid inequality and applications, Journal of Mathematics and Applications, vol. 36, pp. 5-15, 2013.

[6] H. Budak And M. Z. SARIKaya, On generalization of Dragomir's inequalities, Turkish Journal of Analysis and Number Theory, 2017, Vol. 5, No. 5, 191-196.

[7] H. BUDAK AND M. Z. SARIKAYA, New weighted Ostrowski type inequalities for mappings with first derivatives of bounded variation, Transylvanian Journal of Mathematics and Mechanics (TJMM), 8 (2016), No. 1, 21-27.

[8] H. BUDAK AND M. Z. SARIKAYA, A new generalization of Ostrowski type inequalities for mappings of bounded variation, Lobachevskii Journal of Mathematics, 39(9), 2018, pp. 1320-1326.

[9] H. BUdAK AND M. Z. SARIKAYA, On generalization of weighted Ostrowski type inequalities for functions of bounded variation, Asian-European Journal of Mathematics, 11(4), 2018, 1850049 (11 pages).

[10] H. BUdAK AND M. Z. SARIKAYA, A new Ostrowski type inequality for functions whose first derivatives are of bounded variation, Moroccan Journal of Pure and Applied Analysis2(1)(2016), 1-11.

[11] H. BUDAK AND M. Z. SARIKAYA, A companion of Ostrowski type inequalities for mappings of bounded variation and some applications, Transactions of A. Razmadze Mathematical Institute, 171(2), 2017, 136-143.

[12] H. Budak, M. Z. SARIKAYA AND A. QAYYUM, Improvement in companion of Ostrowski type inequalities for mappings whose first derivatives are of bounded variation and application, Filomat, 31:16 (2017), 5305-5314. 
[13] H. BudAK AND M. Z. SARIKAYA, Some perturbed Ostrowski type inequalities for functions whose first derivatives are of bounded variation, International Journal of Analysis and Applications, 11(2), 2016, 146-156.

[14] H. Budak, M. Z. Sarikaya, A. AkKurt And H. Yildirim, Perturbed companion of Ostrowski type inequality for functions whose first derivatives are of bounded variation, Konuralp Journal of Mathematics, 5(1), pp:161-175, 2017.

[15] P. Cerone, S. S. Dragomir, And C. E. M. Pearce, A generalized trapezoid inequality for functions of bounded variation, Turk J Math, 24 (2000), 147-163.

[16] S. S. DRAGOMIR, Approximating real functions which possess nth derivatives of bounded variation and applications, Computers and Mathematics with Applications56(2008), 2268-2278.

[17] S. S. DRAGomir, On trapezoid quadrature formula and applications, Kragujevac J. Math., vol. 23, pp. 25-36, 2001.

[18] S. S. DRAGOMIR, On the midpoint quadrature formula for mappings with bounded variation and applications, Kragujevac J. Math., vol. 22, pp. 13-19, 2000.

[19] S. S. DRAGOMIR, The Ostrowski integral inequality for mappings of bounded variation, Bulletin of the Australian Mathematical Society, 60(1)(1999),495-508.

[20] S. S. DRAGOMIR, On the Ostrowski's integral inequality for mappings with bounded variation and applications, Mathematical Inequalities \& Applications, 4(2001),no. 1, 59-66.

[21] S. S. Dragomir, A companion of Ostrowski's inequality for functions of bounded variation and applications, International Journal of Nonlinear Analysis and Applications, 5(2014) No. 1, 89-97 pp.

[22] S. S. DRAGOMIR, Refinements of the generalised trapezoid and Ostrowski inequalities for functions of bounded variation, Arch. Math. (Basel) 91 (2008), no. 5, 450-460.

[23] S. S. DRAGomir, Some perturbed Ostrowski type inequalities for functions of bounded variation, Asian-European Journal of Mathematics, 8(4), 2015, 14 pages.

[24] S. S. DRAGOMIR, Some perturbed Ostrowski type inequalities for absolutely continuous functions (I), Acta Universitatis Matthiae Belii, series Mathematics 23 2015, 71-86.

[25] S. S. Dragomir, Some perturbed Ostrowski type inequalities for absolutely continuous functions (II), Acta Universitatis Apulensis, 43, 2015, 209-228.

[26] S. S. Dragomir, Some perturbed Ostrowski type inequalities for absolutely continuous functions (III), TJMM, 7(1), 2015,31-43.

[27] S. S. DRAGOMIR, Perturbed companions of Ostrowski's inequality for functions of bounded variation, RGMIA Research Report Collection, 17(2014), Article 1, 16 pp.

[28] S. S. DRAGOMir, Perturbed companions of Ostrowski's inequality for absolutely continuous functions (I), Annals of West University of Timisoara - Mathematics and Computer Science, LIV, 1, (2016), $119-138$.

[29] S. S. DRAgomir, Perturbed companions of Ostrowski's inequality for absolutely continuous functions (II), GMIA Research Report Collection, 17, 2014, Article 19, 11 pp.

[30] W. LIU AND Y. SUN, A Refinement of the Companion of Ostrowski inequality for functions of bounded variation and Applications, arXiv:1207.3861v1, 2012.

[31] W. LIU AND J. PARK, Some perturbed versions of the generalized trapezoid inequality for function of bounded variation, J. Comp. Analy. App. 22(1), 2017, pp.11-18.

[32] A. M. OstrowsKI, Über die absolutabweichung einer differentiebaren funktion von ihrem integralmittelwert, Comment. Math. Helv. 10(1938),226-227.

[33] M. Z.Sarikaya, H. Budak, T. Tunc, S. Erden and H. Yaldiz, Perturbed companion of Ostrowski type inequality for twice differentiable functions, Facta Universitatis, Series: Mathematics and Informatics, 31(3), 2016, 593-607.

[34] M. Z. SARIKAYA, H. BUdAK AND A.QAYYUM, An improved version of perturbed companion of Ostrowski type inequalities, Journal of Inequalities and Special Functions, 7(3), 2016, 12-25.

[35] M.Z. SARIKAYA, H. BUDAK, S. ERDEN AND A. QAYYUM, A generalized and refined perturbed version of Ostrowski type inequalities, International Journal of Analysis and Applications, 13(1), (2017), $70-81$.

[36] K-L TSEnG, G-S YANG, AND S. S. DRAGOMIR, Generalizations of weighted trapezoidal inequality for mappings of bounded variation and their applications, Mathematical and Computer Modelling 40 (2004) 77-84.

[37] K-L TSENG, Improvements of some inequalites of Ostrowski type and their applications, Taiwan. J. Math. 12 (9) (2008) 2427-2441. 
[38] K-L Tseng, S-R Hwang And S. S. Dragomir, Generalizations of weighted Ostrowski type inequalities for mappings of bounded variation and applications, Computers and Mathematics with Applications, 55(2008), 1785-1793.

[39] K-L Tseng, S-R Hwang, G-S Yang And Y-M Chou, Improvements of the Ostrowski integral inequality for mappings of bounded variation I, Applied Mathematics and Computation 217 (2010) $2348-2355$.

[40] K-L Tseng, S-R Hwang, G-S YANG And Y-M Chou, Weighted Ostrowski integral inequality for mappings of bounded variation, Taiwanese J. of Math., Vol. 15, No. 2, pp. 573-585, April 2011.

[41] K-L TSENG, Improvements of the Ostrowski integral inequality for mappings of bounded variation II, Applied Mathematics and Computation 218 (2012) 5841-5847. 